ской Федерации от 29 октября 2010 года // СПС «Гарант».

7. Системы газораспределения. Сети газопотребления. Общие требования к эксплуатации. Эксплуатационная документация. Национальный стандарт РФ. ГОСТ 54961. - М., 2012.

8. Соловъева Е.Б., Харламова Н.А. Определение объема выбросов газа из мест расположения надземных газопроводов // Научное обозрение. 2013. - № 5. - С. 94-98.

9. СП 42.101.2003. Общие положения по проектированию и строительству газораспредели- тельных систем из металлических и полиэтиленовых труб. - М., 2004.

Соловьева Елена Борисовна, канд. техн. наук, доцент кафедры «Теплогазоснабжение и вентиляция», Национальный исследовательскийМосковский государственный строительный университет, Россия.

129337, г. Москва, Ярославское шоссе, 26.

Тел.: (495) 781-80-07.

Ключевые слова: низкое давление; потребители; расчетный перепад давления; газ; газовые приборы.

\title{
ANALYSIS OF PRESSURE CHANGES IN GAS NETWORKS
}

Solovyeva Elena Borisovna, Candidate of Technical Sciences, Associate Professor of the chair "Heat and Gas Supply and Ventilation", Moscow State University of Civil Engineering. Russia.

Keywords: low pressure; consumers; calculated pressure drop; gas; gas appliances.
The paper considers various fluctuations in gas pressure at consumers, which depend on the magnitude of the calculated differential and the degree of its use in the path of gas movement from the feed point to the gas-using unit.

удК 697.2

\section{ТЕПЛОМАССОПЕРЕНОС В КОНДЕНСАЦИОННЫХ ТЕПЛОГЕНЕРАТОРАХ МАЛОЙ МОЩНОСТИ}

\author{
ЧУЛЕНЁВ Анатолий Сергеевич, Нацииональный исследовательский Московский \\ государственный строительный университет
}

Рассматривается и анализируется физико-математическая модель теплообмена на поверхностях конденсации котлов. Проведены исследования профилей температур и парииального давления компонентов, содержащихся в потоке продуктов сгорания на поверхности конденсащии. Для физико-математических модельных критериев получены обобщенные и частные зависимости (для конкретных конструкций теплообменных устройств). Получены качественные стандарты влияния критериев на общую производительность конденсационных поверхностей нагрева котлов малой мощцости.

Введение. Термодинамические процессы тепло- и массопереноса в конденсационных поверхностях нагрева (имеющих низкую температуру) конденсационных теплогенераторов малой мощности зависят от интенсивности процесса конденсации водяных паров из дымовых газов и сопровождаются теплопереносом при переносе массы, что объясняется переносом явной теплоты и выделением скрытой теплоты парообразования.

Рассматривая конденсационную часть теплообменника теплогенератора, можем утверждать, что конденсация будет происходить на охлаждаемой поверхности, тем- пература которой должна быть меньше температуры точки росы продуктов сгорания топлива (т.е. температуры насыщения при постоянном давлении). На поверхности при этом образуется пленка конденсата [6].

Методика исследований. Разработка физической модели тепломассопереноса при кратковременном описании процесса может быть рассмотрена для слоя $d x \cdot l z$ плоскости, движущейся в канале дымовых газов. Таким образом, имеет место тепломассоперенос на поверхности конденсатной пленки с образованием условного пограничного слоя в потоке дымовых газов. 
На поверхности пленки конденсата конденсируется водяной пар и, таким образом, уменьшается парциальное давление $P_{\text {вп }}$ в «фиктивном» пограничном слое, а это соответственно приводит к увеличению парциального давления сухих дымовых газов $P_{\text {сдг, }}$, вызывая взаимную встречную направленность рассматриваемых градиентов парциальных давлений $\operatorname{grad} P_{\text {вп }}$ и $\operatorname{grad} P_{\text {сдг }}$ и, соответственно, их встречную молекулярную и турбулентную диффузию.

Температура дымовых газов $T_{\text {г }}$ приниматься выше $T_{p}$ с более высоким падением внутри условного пограничного слоя до температуры насыщения на поверхности конденсатной пленки [5].

Анализ процесса теплопередачи при формировании модели позволяет для квазистационарных условий для элементарного объема $\mathrm{d} x \mathrm{~d} y \mathrm{l} z$ рассматривать тепломассоперенос только в пределах газового потока, локализуя его на поверхности пленки конденсата (рис. 1). В принятых обозначениях $1 z$ является характерным размером канала.

Таким образом, по полученной физической модели тепломассообмена в конденсационных поверхностях нагрева с помощью методик теории подобия была получена критериальная зависимость для конденсационных теплогенераторов, работающих на газообразном топливе:

$$
\mathrm{St}^{*}=f\left(\operatorname{Re}_{f} ; \operatorname{Pr} ; \frac{t_{\mathrm{r}}-t_{p}}{t_{\text {ст }}} ; \frac{h_{\mathrm{\kappa}}}{d_{\ni}}\right),
$$

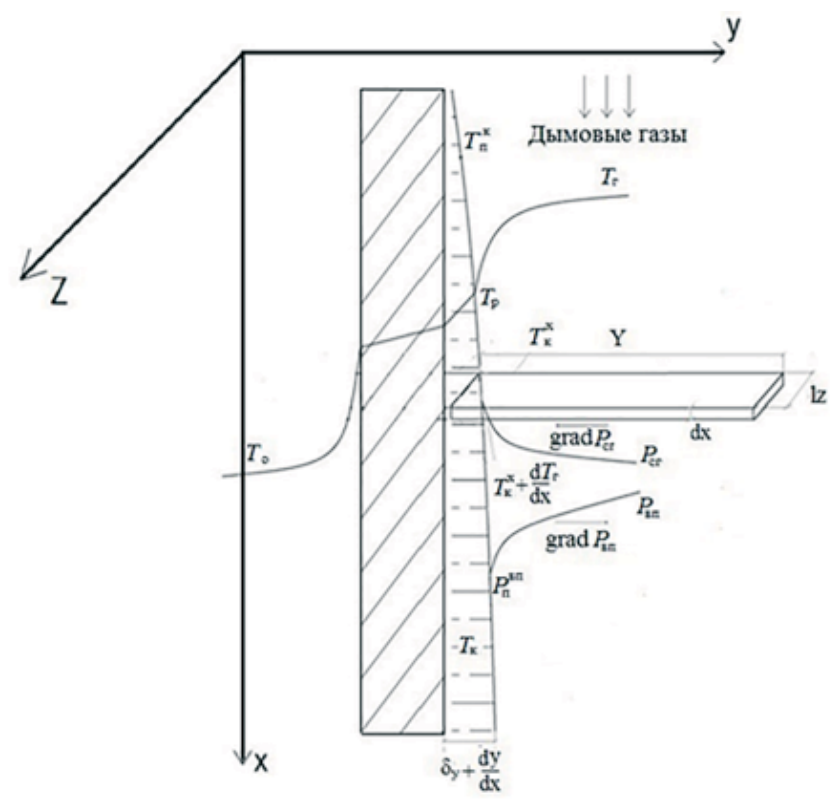

Рис. 1. Физическая модель тепло- и массопереноса эта зависимость позволяет обобщить экспериментальные данные для различных режимов работы конденсационных котлов малой мощности и получить обобщающую зависимость для определения эффективности теплообмена в конденсационных поверхностях котлов в виде функции:

$$
\mathrm{St}^{*}=A \cdot \operatorname{Re}_{f}^{m} \cdot \operatorname{Pr}^{n} \cdot\left(\frac{t_{\mathrm{r}}-t_{p}}{t_{\text {ст }}}\right)^{k} \cdot\left(\frac{h_{\kappa}}{d_{\ni}}\right)^{l} .
$$

Результаты проведенных экспериментов на конденсационных котлах малой мощности показали зависимость:

$\mathrm{St}^{*}=0,0414 \cdot \operatorname{Re}_{f}^{0,55} \cdot \operatorname{Pr}^{-0,47} \cdot\left(\frac{T_{\mathrm{r}}-T_{p}}{T_{\text {ст }}}\right)^{0,24}\left(\frac{h_{\kappa}}{d_{\ni}}\right)^{0,57}$.

Не менее важным представляется вопрос влияния режима работы котла на его КПД. С целью определения зависимости были проведены испытания для газового настенного конденсационного котла с двухсекционным спиральным теплообменником из нержавеющей стали и «примексной» горелкой (полного предварительного смешения).

Результаты исследований. Интерес вызывает определение эффективности работы конденсационной части котла при различных температурах теплоносителя на входе в эту поверхность (температуры так называемой обратной воды), следовательно, с различными условиями теплообмена на холодной поверхности, т.е. с различной долей конденсации водяных паров из продуктов сгорания.

Для определения потерь теплоты с уходящими газами $Q_{2}$ опытным путем были получены значения температуры уходящих газов $t_{\mathrm{yx}}$, расход топлива $B$ и замерен выпавший за время опытов конденсат. С помощью этих значений по id-диаграмме продуктов сгорания была определена энтальпия уходящих газов $I_{\text {ух }}$.

Потери теплоты с уходящим газами [2-4] определяются как разность энтальпий продуктов сгорания на выходе из котельного агрегата и холодного воздуха: где

$$
\begin{gathered}
\mathrm{Q}_{2}=I \alpha_{B}, \kappa Д ж / \mathrm{M}^{3} ; \\
\mathrm{Q}_{2}=I_{y x}-\alpha I_{B}, \kappa Д Ж ~ / \mathrm{M}^{3} ;
\end{gathered}
$$

где $\alpha$ - коэффициент избытка воздуха; 
$I_{\text {в }}$ - энтальпия теоретически необходимого количества воздуха, кДж/ $\mathrm{M}^{3}$.

Тогда относительные потери теплоты с уходящими газами по высшей теплоте сгорания будут равны

$$
q_{2}=\frac{q_{2}}{Q_{\mathrm{E}}^{\mathrm{p}}}
$$

В результате, с учетом отсутствия потерь от механического недожега $q_{4}$ и потерь со шлаком $q_{6}$ КПД конденсационного котла будет равен:

$$
\eta=1-q_{2}-q_{3}-q_{5}
$$

В процессе эксперимента определяли значения температуры уходящих газов $t_{\mathrm{yx}}$ и их энтальпии $I_{\text {ух }}$ (рис. 2).

По полученным величинам рассчитывали значения $q_{2}$ и КПД теплогенератора для температур теплоносителя $t_{\text {тепл }}$ (рис. 3 ).

Заключение. Полученные в ходе экспериментов данные позволяют проследить зависимость увеличения эффективности работы котла (КПД) при уменьшении температуры обратной воды [1]. Необходимо отметить, что полученные в результате испытаний данные показывают зависимость КПД конденсационного теплогенератора в эксплуатационных условиях от количества сконденсировавшихся водяных паров из дымовых газов, т.е. от режима эксплуатации по температуре обратной воды.

\section{СПИСОК ЛИТЕРАТУРЫ}

1. Брюханов О.Н., Шевченко С.Н. Тепломассообмен: учебник. - М., 2014. - 464 с.

2. СП 41-104-2000. Проектирование автономных источников теплоснабжения. - Режим доступа: http://docs.cntd.ru/.

3. Табунщиков Ю.А. Конденсационные котлы в автономном теплоснабжении // АВОК. - 2016. № 4.

4. Хаванов П.А., Маркевич Ю.Г., Чуленёв А.С. Физико-математическая модель теплообмена в конденсационных поверхностях теплогенераторов // Интернет-Вестник ВолгГАСУ. - 2014. № 4(35). - C. 22-26.

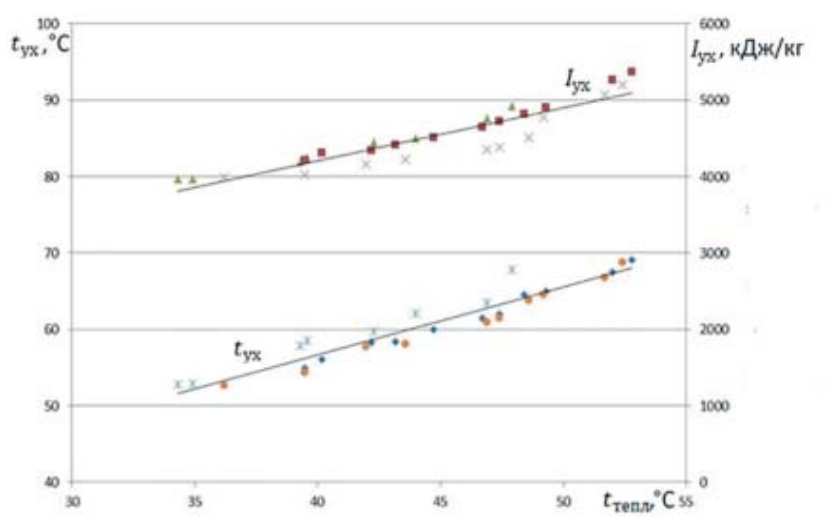

Рис. 2. Влияние температуры обратной воды $\boldsymbol{H a} \boldsymbol{t}_{y x} \boldsymbol{u} I_{y x}$

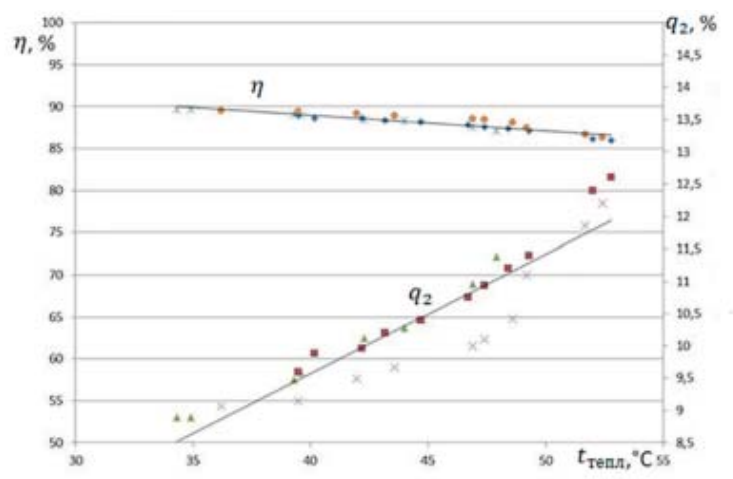

\section{Рис. 3. Влияние температуры обратной воды на q $и$ КПД}

5. Хаванов П.А., Чуленёв А.С. Принципиальные тепловые схемы автономных источников теплоснабжения с конденсационными котлами // АВОК: Вентиляция, отопление, кондиционирование воздуха, теплоснабжение и строительная теплофизика. - 2018. - № 1.

6. Khavanov P.A., Chulenyov A.S. Air pollution by emissions of heat sources. ARPN Journal of Engineering and Applied Sciences, Vol. 13, No. 7, April 2018.

Чуленёв Анатолий Сергеевич, канд. техн. наук, доцент кафедры «Теплогазоснабжение и вентиляция», Национальный исследовательский Московский государственный строительный университет, Россия.

129337, г. Москва, Ярославское шоссе, 26.

Тел.: (495) 781-80-07.

Ключевые слова: теплообмен; конденсационный котел; массоперенос.

\section{HEAT AND MASS TRANSFER IN LOW POWER CONDENSATION HEAT GENERATORS}

Chulenyov Anatoly Sergeevich, Candidate of Technical Sciences, Associate Professor of the chair "Heat and Gas Supply and Ventilation", National Research Moscow State University of Civil Engineering. Russia.

Keywords: heat transfer; condensing boiler; mass transfer.

A physical and mathematical model of heat exchange on the condensation surfaces of boilers is considered and ana- lyzed. The profiles of the temperature and partial pressure of the components contained in the flow of combustion products on the condensation surface were studied., Generalized and partial dependencies (for specific designs of heat exchangers) are obtained for physical and mathematical model criteria. Qualitative standards of the influence of criteria on the overall performance of condensing heating surfaces of low-power boilers have been obtained. 